\title{
Influence of Ocean-Atmosphere Interaction on the Arctic Oscillation in Two General Circulation Models
}

\author{
ANDREW W. ROBERTSON \\ Department of Atmospheric Sciences and Institute of Geophysics and Planetary Physics, University of California, Los Angeles, \\ Los Angeles, California
}

(Manuscript received 17 August 2000, in final form 18 January 2001)

ABSTRACT

\begin{abstract}
The influence of ocean-atmosphere interaction on the wintertime Arctic oscillation (AO) is investigated using a hierarchy of experiments made with two general circulation models (GCMs), ranging from climatologically forced atmospheric to fully coupled ocean-atmosphere GCMs with increasing greenhouse gas concentrations.

Both GCMs reproduce well the AO spatial pattern, defined by the leading hemispheric mode of monthly sea level pressure or daily 700 -hPa geopotential height, although the North Pacific pole is more pronounced as compared with observations. Coupling is not found to influence this spatial pattern.

Power spectra are examined for evidence of ocean-atmosphere interaction in the form of spectral reddening or significant spectral peaks. No measurable influence is found. On interannual timescales, all the model AO spectra are approximately "white," with no clear evidence of any statistically significant spectral peaks in the coupled experiments. Greenhouse gas-induced changes in sea level pressure are found to project onto the AO in one of the GCMs but not the other. On subseasonal timescales, the spectra are "red" in all the model configurations, but ocean-atmosphere interaction is not found to amplify the redness. Significant spectral peaks are found in the 15-25-day period range, consistent with observed spectra.

Daily histograms of the simulated AO indices are found to be negatively skewed. A Gaussian mixture model is used to estimate the probability density function of daily hemispheric height maps, and yields three circulation regimes in both the simulations and observed data. The uncoupled atmospheric GCM simulations exhibit AOlike regimes that acquire stronger wavelike characteristics in the coupled runs.
\end{abstract}

\section{Introduction}

The Arctic oscillation (AO) emerges as the leading empirical mode of wintertime monthly sea level pressure (SLP) over the Northern Hemisphere (NH) (Lorenz 1951; Kutzbach 1970; Trenberth and Paolino 1981; Wallace and Gutzler 1981; Thompson and Wallace 1998). Its spatial structure is characterized by anomalous SLP of one sign throughout the Arctic Basin, with anomalies of the opposite sign centered over the Azores and, more weakly, over the North Pacific (see Fig. 1f). The AO index - which is highly correlated with the North Atlantic oscillation (NAO) index so that the two are arguably almost synonymous (Deser 2000)—has exhibited large decadal-scale near-cyclic variations over the past 30 years (see Fig. 2b), together with an upward trend. Through advection, the circulation pattern exerts a strong impact on wintertime surface temperature, precipitation, and storminess over Europe (e.g., Hurrell 1995).

Corresponding author address: Andrew W. Robertson, Department of Atmospheric Sciences, University of California, Los Angeles, 405 Hilgard Ave., Los Angeles, CA 90095-1565.

E-mail: andy@atmos.ucla.edu
It is presently unknown whether this recent temporal evolution contains a deterministic component that would hence be potentially predictable. In the context of the observed NAO record, which is at best about 175 years long, two studies of its statistical properties have argued that the index's recent behavior is not statistically significantly different from noise (Wunsch 1999; Stephenson et al. 2000).

If, on the other hand, an underlying deterministic near-decadal component does exist, interactions with the ocean are a leading contender for an explanation. Recent ensemble simulations with atmospheric general circulation models (GCMs) suggest that the NAO's decadal evolution can be partly reproduced - at least in phase if not in amplitude-by prescribing the observed global evolution of sea surface temperatures (SSTs) and sea ice (Rodwell et al. 1999; Mehta et al. 2000). This type of atmospheric GCM experiments has been criticized as unphysical by Bretherton and Battisti (2000) because an SST evolution is prescribed, giving rise to anomalous midlatitude air-sea heat fluxes that are of the wrong sign when compared with those that would be obtained in a coupled system; they also point out that there is not necessarily any implied predictability associated with the ocean, because midlatitude SSTs are largely a 
a) ECHAM3 $(32.3 \%)$

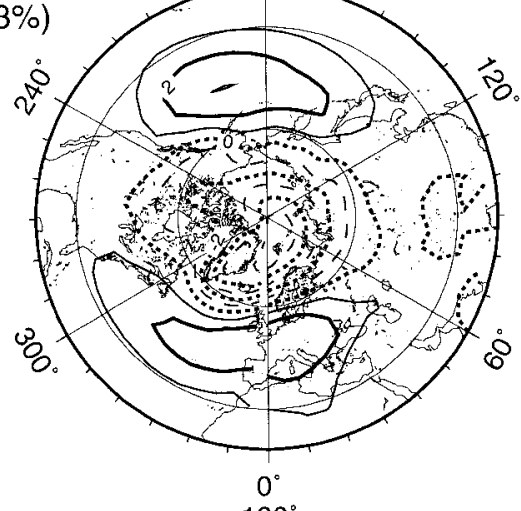

c) ECHAM4/OPYC CTRL $180^{\circ}$ $(23.9 \%)$

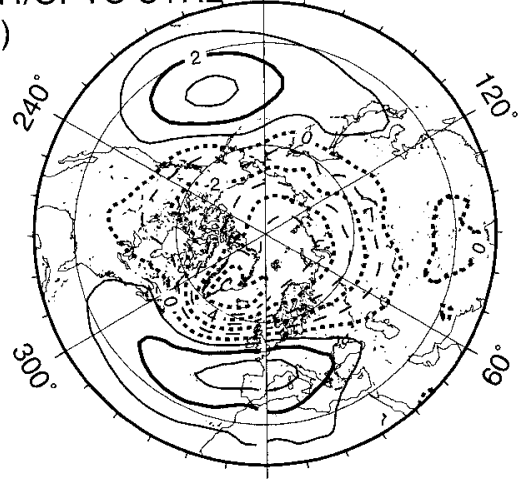

$0^{\circ}$

e) ECHAM4/OPYC GHG,

$(23.7 \%)$

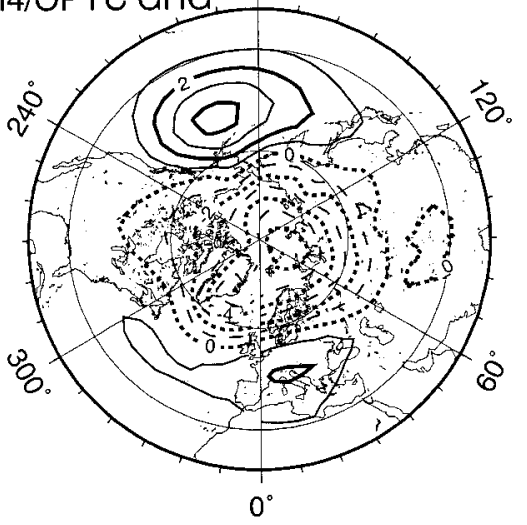

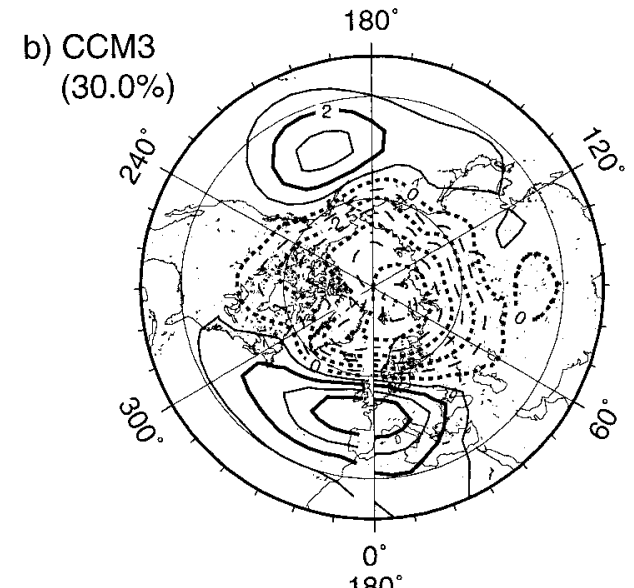

d) CSM
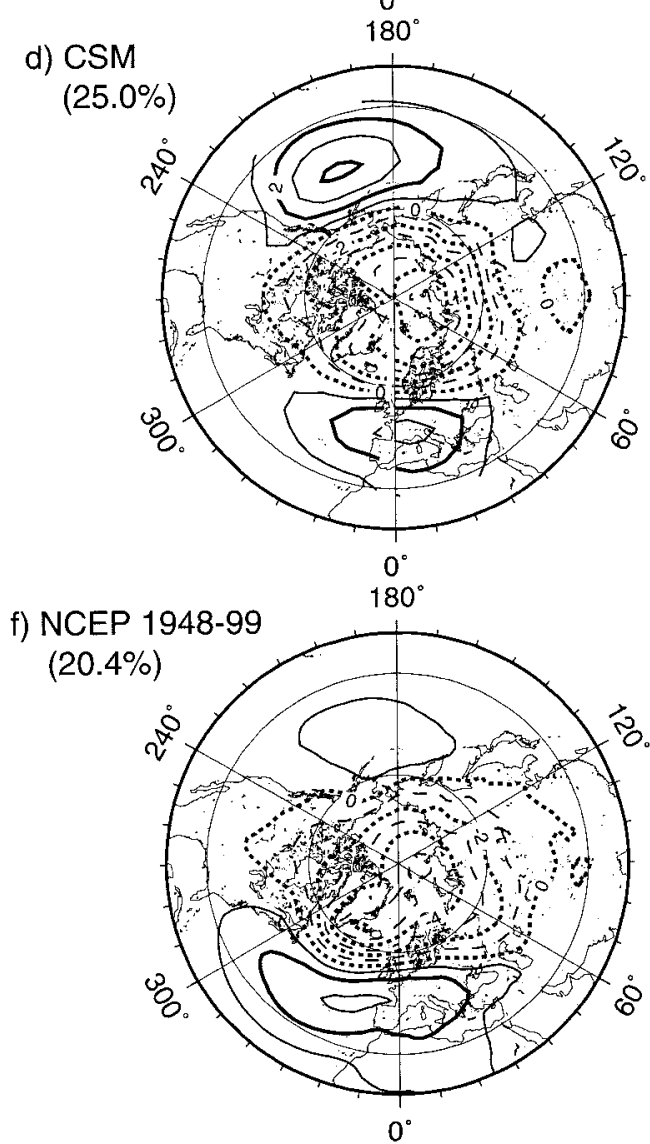

FIG. 1. Leading NH monthly EOF (Nov-Apr) of SLP. (a) ECHAM3 (uncoupled), (b) CCM3 (uncoupled), (c) ECHAM4/ OPYC control, (d) CSM (control and GHG simulations concatenated together), (e), ECHAM4/OPYC GHG run, and (f) NCEP-NCAR reanalysis. The contour interval is $1 \mathrm{hPa}$, and the zero and negative contours are dashed. The variance of the associated PC is given in brackets; PC-2 (not shown) accounts for $10.3 \%, 9.7 \%, 11.3 \%, 12.2 \%, 12.6 \%$, and $11.8 \%$ variance in the six cases, respectively. In (a), SLP was derived from $1000-\mathrm{hPa}$ geopotential height $(Z)$ using the approximate relationship $P-1000=Z / 8$, where $Z$ is expressed in meters and $P$ in hectopascals.

product of the atmosphere itself. These experiments do, nonetheless, indicate some sensitivity to the ocean, whether this be in the midlatitudes or Tropics.

The aim of this paper is to examine the role of oceanatmosphere interaction on the AO using coupled oceanatmosphere GCMs. By comparing fully coupled simu- lations with those made with the atmospheric component of the models alone with climatological SSTs prescribed, the role of the ocean should be clear. If GCMs can simulate the $\mathrm{AO}$ adequately, multicentury simulations also have, in addition, the potential to determine the AO's power spectrum with higher statistical confi- 
a) SSA Spectrum

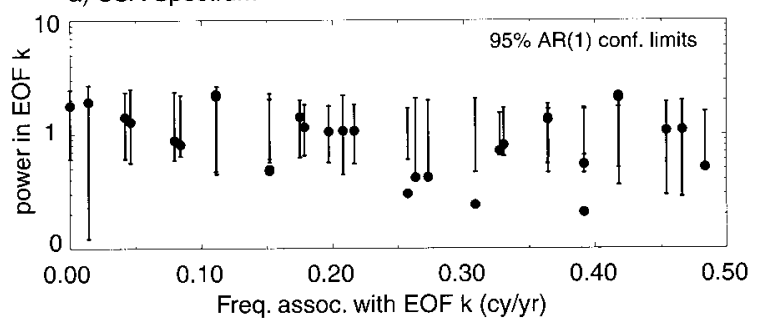

b) Reconstructed Components

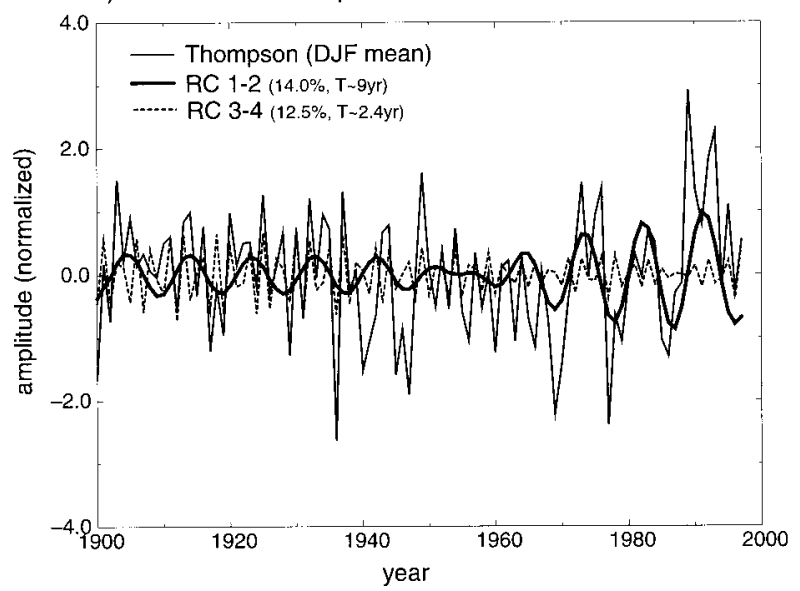

FIG. 2. An SSA of the DJF-mean observed AO index of Thompson and Wallace (2000) for 1899/1900-1996/97. (a) SSA power spectrum using a window width of $M=30 \mathrm{yr}$, with normalized power in temporal EOF $k$ on the ordinate and the dominant associated frequency of temporal EOF $k$ along the abscissa. The error bars denote the $95 \%$ confidence interval of a red noise null hypothesis, computed using a chi-square test. (b) The original series with the two leading pairs of reconstructed components superposed; the variance and approximate period of each are given in brackets. The approximate spectral resolution is $1 / 30$ cycles per year.

dence than can be done with the relatively short observational record. The AO paradigm is chosen here, rather than the NAO one, so as to take a general hemispheric measure of variability, rather than a sectorial one, and because both the GCMs considered here do simulate a more pronounced AO pattern than in nature; thus the AO is arguably more relevant to the GCM simulations than to the observed record.

The AO, like other atmospheric teleconnection patterns, appears to to be an intrinsic mode of the atmosphere with a timescale on the order of a week (e.g., Feldstein 2000). Ocean-atmosphere interaction can potentially influence both its spatial structure and temporal evolution. Empirical orthogonal functions (EOFs) of monthly hemispheric SLP will be used to characterize spatial structure, as well as recurrent circulation regimes defined from the probability density function (PDF) of daily hemispheric geopotential height maps. The leading EOF of SLP has been shown to represent the AO well (Thompson and Wallace 1998). However, several dif- ferent approaches can be taken to project climate variability onto a few "modes." The multiple-regimes approach is attractive because it involves no linearity assumption.

Power spectra of the AO's principal component time series will be used to examine temporal evolution. Two types of temporal changes may result from oceanic coupling. Coupling could potentially produce a spectral peak, either through "loop-type" oscillations (e.g., Latif and Barnett 1994) or through "spatial resonance" (e.g., Saravanan and McWilliams 1997). Coupling can also "redden" the shape of the spectrum by reducing the thermal damping of the atmosphere at the sea surface and thus increasing persistence of atmospheric anomalies. This reddening mechanism has been demonstrated in a simple stochastically forced 1D atmospheric energy-balance model coupled to an oceanic mixed layer (Barsugli and Battisti 1998).

Simulations are analyzed from a hierarchy of uncoupled-atmospheric and coupled ocean-atmosphere GCMs from two modeling centers; the models and simulations are presented in section 2 and are summarized in Table 1. I examine the spatial structure of simulated AO-like variability and its power spectrum, first using monthly SLP (section 3), and second in terms of daily 700-hPa geopotential height fields (section 4). A summary and discussion are given in section 5 .

\section{The GCMs}

Two different GCMs are considered. The first is the National Center for Atmospheric Research (NCAR) Climate System Model (CSM), version one, which consists of the Community Climate Model, version 3 (CCM3), atmospheric GCM and the NCAR CSM ocean model (NCOM), run without flux correction (Boville and Gent 1998). Monthly data are available from this model. The second is the ECHAM/OPYC suite of models from the Max Planck Institute for Meteorology in Hamburg, Germany (Roeckner et al. 1999). Daily data are also readily available for this model, enabling the additional analysis of subseasonal timescales. Table 1 describes the models, and the set of simulations used. Comparisons with observed data are made using the National Centers for Environmental Prediction (NCEP)-NCAR reanalysis of 1948-99 (Kalnay et al. 1996).

By using two different GCMs, one obtains some measure of the intermodel sensitivity of the results, and partially alleviate the difficulties associated with comparing the uncoupled and coupled models. In the case of the non-flux-corrected CSM, some differences in climate between uncoupled and coupled simulations are inevitable, although these are generally quite small in the variables considered here (Boville and Hurrell 1998). In the flux-corrected Hamburg model, a more recent version of the atmospheric model was used in the coupled simulations. The main differences between ECHAM3 and ECHAM4 are a new radiation scheme 
TABLE 1. Details of the GCM simulations.

\begin{tabular}{|c|c|c|}
\hline Model & $\begin{array}{l}\text { Simulation } \\
\text { years }\end{array}$ & Description \\
\hline ECHAM3 & $1-100$ & $\begin{array}{l}\text { Hamburg uncoupled AGCM } \\
\text { with climatological SSTs }\end{array}$ \\
\hline CCM3 & $1-100$ & $\begin{array}{l}\text { NCAR uncoupled AGCM with } \\
\text { climatological SSTs }\end{array}$ \\
\hline $\begin{array}{l}\text { ECHAM4/OPYC } \\
\text { control }\end{array}$ & $1-300$ & $\begin{array}{l}\text { Hamburg coupled atmosphere- } \\
\text { ocean GCM with fixed GHGs } \\
\text { (flux corrected) }\end{array}$ \\
\hline $\begin{array}{l}\text { ECHAM4/OPYC } \\
\text { GHG }\end{array}$ & $1860-2100$ & $\begin{array}{l}\text { Hamburg coupled atmosphere- } \\
\text { ocean GCM with increasing } \\
\text { GHGs according to IPCC } \\
\text { IS92a scenario (flux corrected) }\end{array}$ \\
\hline CSM control & $1-300$ & $\begin{array}{l}\text { NCAR coupled atmosphere- } \\
\text { ocean GCM (CCM3/NCOM) } \\
\text { with fixed GHGs }\end{array}$ \\
\hline CSM GHG & $1-130$ & $\begin{array}{l}\mathrm{CCM} 3 / \mathrm{NCOM} \text { with } \mathrm{CO}_{2} \text { increas- } \\
\text { ing at } 1 \% \text { per year starting in } \\
\text { year } 10\end{array}$ \\
\hline
\end{tabular}

and new closure for deep convection; both have minor impacts for my purposes (Roeckner et al. 1996).

All fields are for the $\mathrm{NH}$, extend northward from $20^{\circ} \mathrm{N}$, and were area weighted by the square root of cosine latitude. The seasonal cycle was removed at the outset by subtracting the ensemble mean over each calendar month or, in the intraseasonal case, by subtracting an average seasonal cycle, constructed by applying a 5day running mean and averaging over all years.

\section{Intermonthly and interannual variability}

\section{a. Spatial structure}

Figure 1 shows the leading EOF of monthly NH SLP for the November-April extended winter season. In all cases, EOF-1 exhibits a clear AO pattern (Thompson and Wallace 1998). It is well separated in variance from EOF-2 (see caption of Fig. 1) which is characterized by a large anomaly over the Gulf of Alaska with weak wavelike features over North America and resembles the Pacific-North American (PNA) pattern; in the following the PNA/reverse-PNA terminology is used to refer to this kind of feature.

All the model simulations capture the basic observed tripole pattern rather well, and this is consistent with previous GCM studies (e.g., Lau 1981; Fyfe et al. 1999). The intensity of the North Pacific center appears to be exaggerated in both models, making the pattern more symmetric between the two ocean sectors than in observations. However, the observed AO pattern derived by Thompson and Wallace (1998) using a century of data is more annular than the one derived here using the last 50 years alone (see Fig. 4c). The robustness of the Pacific pole in the simulations was verified by splitting the datasets into two halves and repeating the analysis; it is also highly significant according to a Student's $t$ test.

The impact of ocean-atmosphere coupling on the spa-
TABLE 2. Interannual lag-1 autocorrelation $(\gamma)$ of an AR(1) process fit to PC-1 of SLP. The robust estimate is computed from a multitaper method (MTM) estimate of the spectrum smoothed with a median filter of width 0.017 cycles day ${ }^{-1}$, so as to remove narrowband peaks. The 95th percentile of $\gamma$ computed from 1000 Gaussian white noise segments is 0.084 and 0.173 for the raw and robust estimates, respectively.

\begin{tabular}{lrc}
\hline \hline Time series & Raw & Robust \\
NCEP-NCAR reanalysis 1948-99 & 0.320 & 0.415 \\
Thompson and Wallace 1899-1997 & 0.082 & 0.096 \\
ECHAM3 & -0.098 & 0.000 \\
CCM3 Clim. SSTs & 0.005 & 0.015 \\
CCM3 GISST SSTs & -0.120 & 0.000 \\
ECHAM4/OPYC control & -0.022 & 0.065 \\
ECHAM4/OPYC GHG & 0.146 & 0.013 \\
CSM control & 0.040 & 0.131 \\
CSM GHG & -0.018 & 0.156 \\
\hline
\end{tabular}

tial pattern is minimal in both the Hamburg and NCAR models. Coupling slightly decreases the variance of EOF-1 in both models, while that of EOF-2 (a PNAlike pattern) increases slightly (see caption of Fig. 1).

The uncoupled AGCM simulations in Figs. 1a,b use seasonally varying climatological SST distributions at the lower boundary. A CCM3 simulation forced by observed variations in SST 1870-1997 from the Global Sea-Ice and SST data (GISST) dataset (Rayner et al. 1995) was also examined. Its leading EOF of SLP presents a very similar pattern (not shown) to its climatologically forced counterpart in Fig. 1b. In this CCM3GISST simulation, the leading two EOFs account for $25.6 \%$ and $11.6 \%$ of the SLP variance, respectively. These numbers are closer to those of the coupled CSM rather than the uncoupled climatological run, consistent with the expectation that PNA-like variability (EOF-2 in all cases) is more pronounced when SSTs vary over the tropical Pacific.

Greenhouse gas (GHG) forcing has a noticeable impact in ECHAM4/OPYC, with the North Pacific center becoming even more pronounced, and the Azores center weakening. This contrasts with the CSM for which the

TABLE 3. The cross-validated log likelihood of the Gaussian mixture model, with the posterior probability (zero to one) given below it, as a function of $k$.

\begin{tabular}{rrrrr}
\hline \hline$k$ & & & & \\
& & & ECHAM4/ \\
ECHAM4/ & OPYC GHG \\
EPalysis & ECHAM3 & OPYC control & $1860-2100$ \\
\hline 1 & -349.578 & -343.880 & -336.784 & -343.042 \\
& 0.000 & 0.000 & 0.000 & 0.000 \\
2 & -348.701 & -342.733 & -334.826 & -341.843 \\
& 0.002 & 0.000 & 0.000 & 0.000 \\
3 & -348.467 & -342.394 & -333.784 & -341.704 \\
& 0.802 & 1.000 & 1.000 & 0.005 \\
4 & -348.523 & -342.684 & -334.236 & -341.660 \\
& 0.000 & 0.000 & 0.000 & 0.952 \\
5 & -348.919 & -342.556 & -334.108 & -341.686 \\
& 0.000 & 0.000 & 0.000 & 0.040 \\
6 & -348.910 & -342.643 & -334.159 & -341.708 \\
& 0.000 & 0.000 & 0.000 & 0.003 \\
\hline
\end{tabular}


a) $\mathrm{ECHAM} 3$

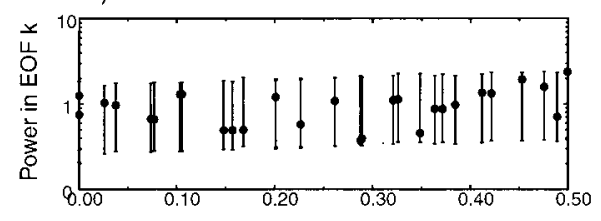

c) ECHAM3/OPYC Control

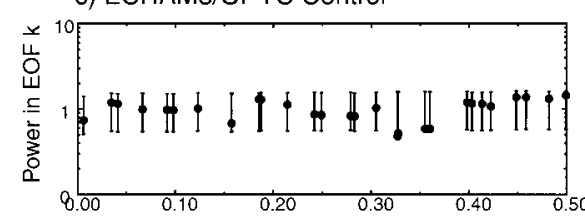

e) ECHAM3/OPYC GHG

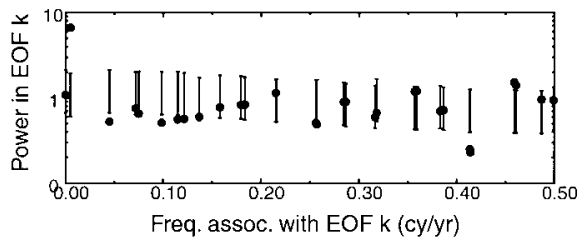

b) $\mathrm{CCM} 3$

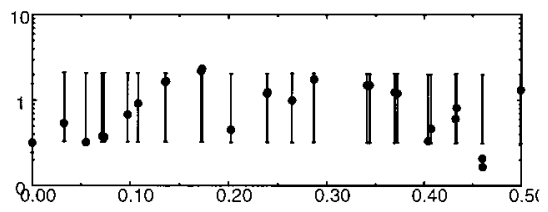

d) CSM Control

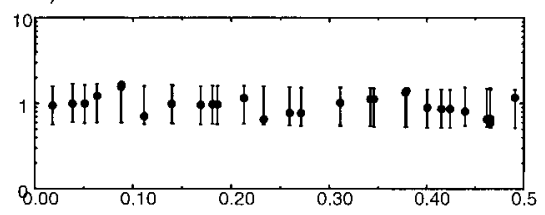

f) CSM GHG

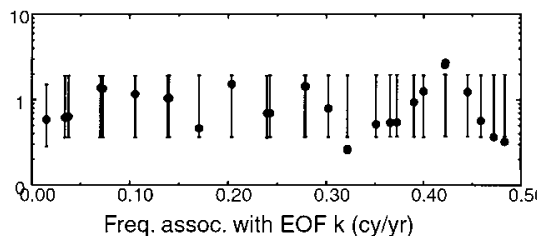

FIG. 3. Interannual SSA power spectra of simulated wintertime mean AO indices, constructed using DJF averages of the monthly SLP PC-1. (a) ECHAM3, (b) CCM3, (c) ECHAM4/OPYC control, (d) CSM control, (e) ECHAM4/OPYC GHG, and (f) CSM GHG. The SSA window width is $M=30 \mathrm{yr}$, with details as in Fig. 2. In (d) and (f), the EOF in Fig. 1d is projected onto the respective CSM experiment.

AO pattern is almost indistinguishable with or without GHGs; thus, the CSM's EOF-1 (Fig. 1d) is shown for the 300-yr control simulation concatenated with the 130yr transient GHG run.

\section{b. Spectrum of the observed $A O$}

The power spectrum of the observed AO is plotted in Fig. 2a, in terms of a singular spectrum analysis (SSA; Vautard and Ghil 1989; Ghil et al. 2001) of the 18991997 AO index of Thompson and Wallace (2000), using December-January-February (DJF) averages. The SSA spectra are eigenvalue spectra of the autocorrelation matrix, with power (i.e., the variance accounted for by each eigenmode) plotted against the dominant associated frequency of the corresponding temporal EOF. A pair of eigenvalues with near-equal variance may indicate the presence of an oscillatory component of the time series, that is, a spectral peak.

Two oscillatory pairs of eigen-elements are identified at periods of about 9.0 and $2.4 \mathrm{yr}$. Assessing statistical significance against a red noise null hypothesis (Allen and Smith 1996), indicates the quasi-biennial mode to be significant at about the $95 \%$ level while the neardecadal mode is not highly significant. The 9.0-yr component was found to be strongest in the DJF season shown. Figure $2 \mathrm{~b}$ shows the AO time series together with reconstructed components (RCs) for each oscillatory pair. The 9.0-yr RC pair is only pronounced since about 1960. Since Arctic data may be not be reliable prior to 1950, the analysis has been repeated using the NAO indices of Hurrell (1995) and the Climatic Research Unit (CRU) of the University of East Anglia, United Kingdom (Jones et al. 1997). The near-decadal component is recovered in both cases with a period of $8.0 \mathrm{yr}$, and is found to be statistically significant at the 95\% level against red noise in the longer (175 yr) CRU series. Repeating the analysis with annual averages of the CRU series recovers a very similar statistically significant component with a period of $7.8 \mathrm{yr}$. The existence of a near-8-yr period over the North Atlantic sector has been known for some time (Rogers 1984); it is also present in North Atlantic SSTs (Moron et al. 1998), the central England temperature record (Plaut et al. 1995), as well as over North America (Dettinger et al. 1995).

The 2.4-yr component is close to the Nyquist frequency and may not be reliable. However, a quasi-biennial component of the $\mathrm{AO}$ has been found in the past (Trenberth and Paolino 1981), and Baldwin and Dunkerton (1999) suggest that the stratospheric quasi-biennial oscillation may tend to excite the AO.

\section{c. Spectra of simulated $A O$ indices}

Figure 3 shows SSA spectra for time series corresponding to the models' EOF-1 in Fig. 1, using DJF averages to match those plotted in Fig. 2. Very similar results are obtained with November-April averages or using the multitaper method (not shown). All the spectra are "white" in appearance. For a quantitative measure, 


\section{a) CSM Control}

\section{b) ECHAM4/OPYC Control}

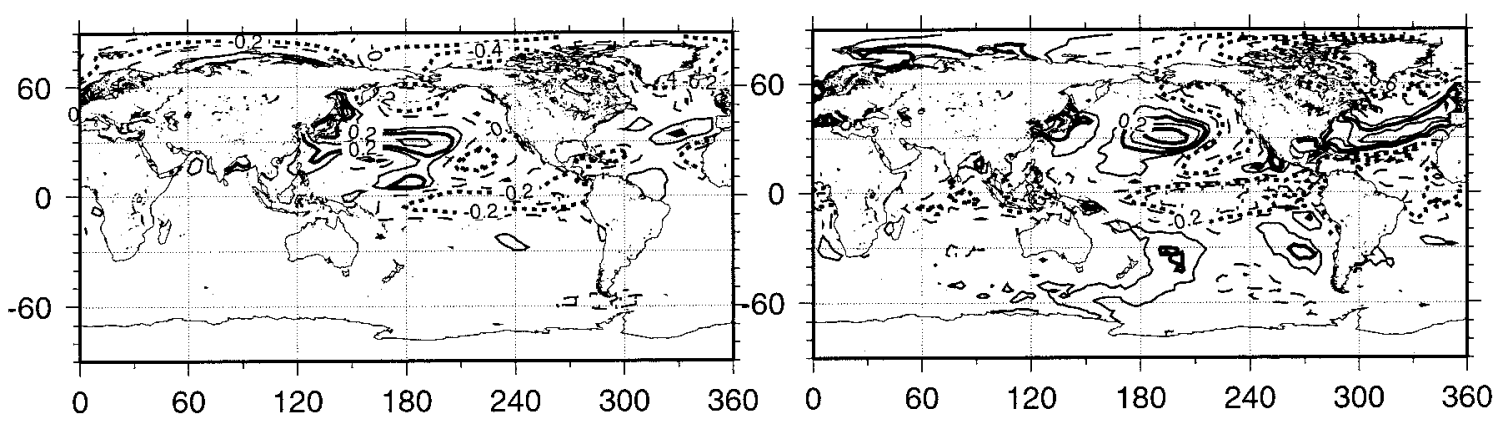

c) OBS

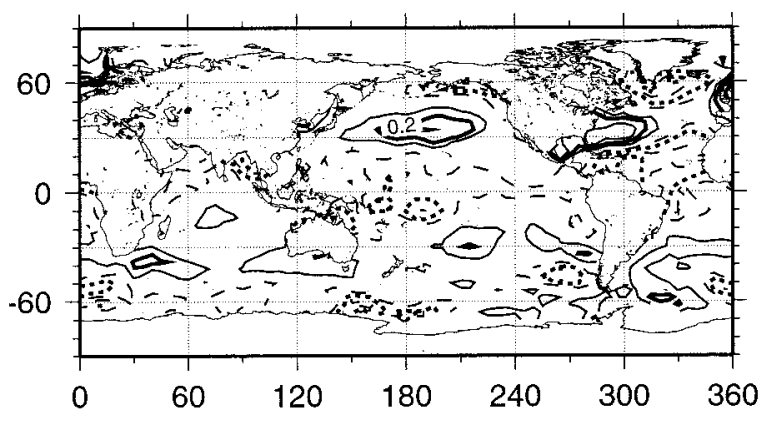

FIG. 4. Correlations between Nov-Apr means of the AO index and SST at each grid point, using PC-1 of (a) CSM control, (b) ECHAM4/ OPYC control, and (c) Thompson and Wallace's (2000) index with the 1904-94 GISST dataset. The 95\% significance threshold for the correlation coefficient in each case is (a) 0.11 , (b) 0.13 , and (c) 0.27 , respectively. These values are computed from a two-sided $t$ test with the number of effective degrees of freedom computed conservatively, following Davis (1976). Contour interval is 0.1.

Table 2 gives the lag-1 autocorrelation coefficient $\gamma$ of an $\mathrm{AR}(1)$ process fitted to each series, together with an estimate of $\gamma$ computed from a robust estimate of the noise following Mann and Lees (1996). In the robust estimate, narrowband spectral features are removed using a median filter, yielding a measure of the background spectrum; its effect can be clearly seen in the Hamburg GHG run, where the trend component is excluded.

Table 2 confirms that none of the GCM spectra differ significantly from white noise; thus coupling does not measurably redden the AO spectrum in either model. The spectrum of the CCM3-GISST run is also white, so that prescribing observed SST variations in an Atmospheric Model Intercomparison Project-style fashion does not measurably influence the AO's spectrum in CCM3. Only the reanalysis data 1948-99 are significantly red, while Thompson and Wallace's (2000) longer observed record is white. Although the spectra in Fig. 3 are normalized, the variances and amplitudes of the EOFs in Fig. 1 indicate that there in no displacement of the entire spectrum toward higher power in the coupled cases. If anything, the variance of the $\mathrm{AO}$ deceases in the coupled runs.

Aside from the overall shape of the spectrum, SSA can identify oscillatory modes that may arise from ocean-atmosphere interactions. Could the 9-yr RC in the observed AO series in Fig. 2 be a result of such coupling? The spectra of the model simulations provide no supportive evidence for this conjecture. Although the CSM does show a weakly significant peak near $12 \mathrm{yr}$ that is not present in the uncoupled CCM, the level of statistical significance is modest considering the $300-y r$ length of the simulation. Thus, neither long coupled GCM exhibits a clear decadal or interdecadal component.

Both GCMs do show some marginally significant interannual components $(T<5 \mathrm{yr})$. Since correlations with SST, plotted in Fig. 4, occur over the equatorial Pacific as well in the coupled models, these peaks may be associated with weak El Niño-Southern Oscillation (ENSO)-like variability. The GCM behavior appears not to be realistic in this respect, since ENSO and the AO are almost unrelated in observed data, as indicated by the absence of SST correlations over the equatorial Pacific in Fig. 4c. The correlations over the northern oceans in Figs. 4a-c are largely consistent with the AO atmospheric anomalies forcing the ocean (e.g., Cayan 1992). The observed correlations with SST over the North Pacific are perhaps surprisingly strong in Fig. 4c, given the weakness of the North Pacific center of the observed AO. However, this map was obtained using Thompson and Wallace's (2000) index (1904-94), which has a stronger Pacific pole than Fig. 1f. 
a) ECHAM4/OPYC GHG

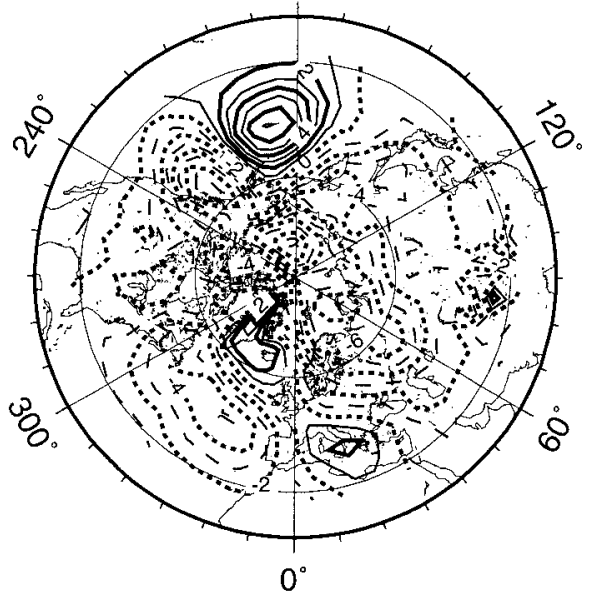

b) CSM GHG

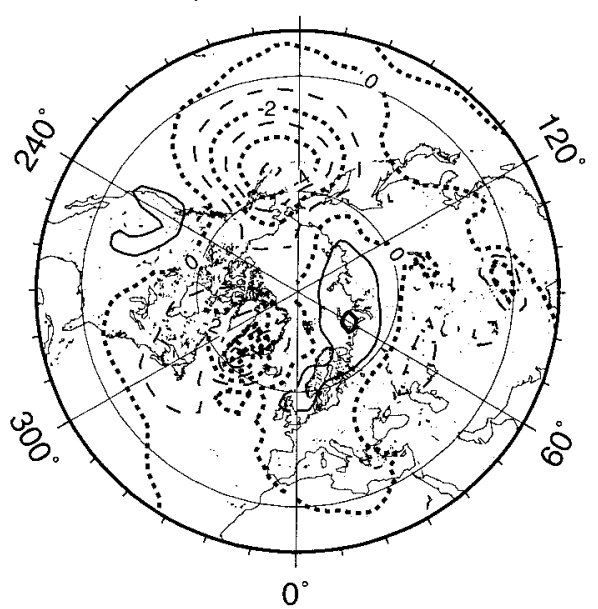

FIG. 5. Linear Nov-Apr SLP trends for (a) ECHAM4/OPYC (1960-2100), and (b) CSM GHG (year 10109). Contour interval is $1 \mathrm{hPa}\left(100 \mathrm{yr}^{-1}\right)$.

\section{d. Greenhouse gas-induced trends}

A recent positive trend is evident in the $\mathrm{AO}$ index and polar night jet (e.g., Graf et al. 1995; Hurrell 1995; Thompson and Wallace 1998), and an upward trend is simulated in some GCM GHG runs (Fyfe et al. 1999; Shindell et al. 1999) but not others (P. Kushner 1999, personal communication). Despite the large degree of similarity in AO structure in the CSM and Hamburg models, the linear SLP trends predicted by the two GCMs under increasing GHG concentrations have contrasting spatial distributions, as illustrated in Fig. 5. These project very differently onto the AO, as demonstrated in Fig. 6, which shows how the linear trends project onto the leading 10 EOFs of the respective coupled control run.

The Hamburg model's trend in SLP clearly projects very strongly onto the AO. However, much of the SLP decreases over the northern continents in Fig. 5a are confined to the planetary boundary layer, so that the trend is less AO-like at $700 \mathrm{hPa}$ (not shown). In addition, at least part of the large AO projection in the Hamburg model appears to be due to changes over the North Pacific.

\section{Intraseasonal variability}

\section{a. Spatial structure}

Atmospheric variability on the timescales of days to weeks has typically been examined at the 700-hPa level because of the longer availability of observed data there. Thus, this level is selected for the analysis of intraseasonal variability. Daily $700-\mathrm{hPa}$ data were only readily available from the Hamburg models, and because of the large volume of the daily data, the analysis of the long coupled runs is restricted primarily to the first $100 \mathrm{yr}$ of the ECHAM4/OPYC control run, and to the the last $100 \mathrm{yr}$ of the GHG run (i.e., the twentyfirst century).

Figure 7 shows the leading EOF of unfiltered daily 700-hPa geopotential height data over the NH for November-March, from the reanalysis, and the Hamburg uncoupled, coupled, and GHG coupled runs. The pattern that emerges is similar to the AO one in SLP shown in Fig. 1, but is more annular. It is less well separated from EOF-2 in variance (see Fig. 7 caption), which again resembles the PNA pattern in all cases. The midlatitude centers of EOF-1 are more zonally elongated and the Arctic pole extends less into the northern continents than in Fig. 1. By repeating the analysis using monthly means of 700-hPa height, these differences in pattern can be traced primarily to the use of daily as opposed to monthly mean data, rather than to the different vertical levels.

In comparison with the reanalysis data, the Hamburg model captures the daily AO pattern very realistically, again with a tendency for the Pacific center to be too strong. As in monthly SLP, there is very little difference in pattern between the uncoupled (Fig. 7b) and coupled (Fig. 7c) models. Thus, to first order, ocean-atmosphere interaction has no impact on modal spatial structure. When increases in greenhouse gases are prescribed through the twenty-first century, the Atlantic pole becomes more confined to Europe.

\section{b. Spectra}

To examine the temporal spectra of the daily November-March EOFs, I construct multiyear continuous time series from the PCs by padding with zeros during the months April-October, and forming 5-day averages. Thus, each time series consists of 735 -day averages per 


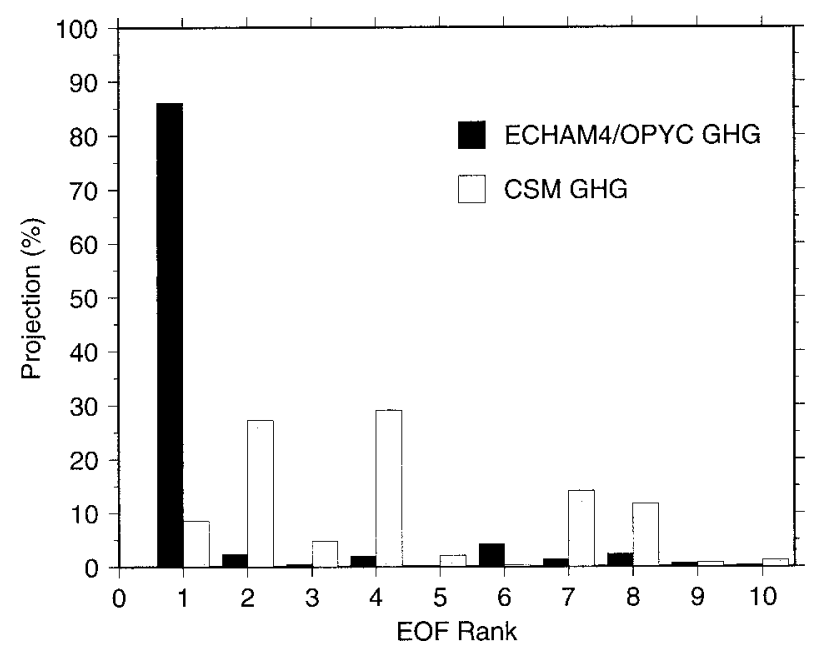

FIG. 6. Projections of linear SLP trends in Fig. 5, north of $20^{\circ} \mathrm{N}$, onto the leading 10 monthly SLP EOFs of the respective coupled control run. The ordinate is in percent of the total projection onto the $10 \mathrm{EOFs}$.

year. SSA is then applied to these 5-day series, and the spectra plotted in Fig. 8.

In contrast to the seasonal-mean spectra, these spectra have a strongly red character. This is also seen clearly in terms of the lag- 1 autocorrelation values, given in the caption of Fig. 8. The shapes of the model spectra match the observed one quite closely. As in the case of seasonal means, there is no clear increase in spectral redness in the coupled runs, compared to the uncoupled one.

All the 5-day AO spectra-both simulated and observed-exhibit statistically significant spectral peaks (i.e., pairs of eigenvalues) in the 15-25-day period range. The models appear to capture these intraseasonal oscillations, which previous work suggests may be associated with mountain torque forcing (Lott et al. 2001). However, there are clearly some differences in the locations of the peaks (i.e., pairs of eigenvalues) and the overall shape of the spectra between the model simulations, over and above what would be expected from sampling variations, given that submonthly variability is very well sampled. The spectra do deviate from the AR(1) null hypothesis at higher frequencies, especially in the GHG case.

\section{c. Histograms}

Histograms of the daily PC-1 time series are plotted in Fig. 9, (without 5-day averaging). All the distributions are moderately skewed toward the negative polarity of the AO, with a skewness that exceeds several times its own standard deviation (see caption of Fig. 9).

On physical grounds and by analogy with stratospheric warmings, radiational constraints control the maximum coldness and depth that the polar vortex can attain, while it is possible to fill it in very efficiently by poleward advection of warmer air (see also Gillett et al. 2001). Similarly, a positive AO corresponds to an intensified midlatitude jet stream whose strength must be bounded because of surface drag. Previous studies (White 1980; Nakamura and Wallace 1991) have shown that skewness in local SLP tends to be positive on the poleward side of the mean jet stream position, and negative to the south of it. This is interpreted in terms of airmass cutoffs on either side of the jet. It is consistent with the negative skewness of the AO in Fig. 9, since the Arctic pole (negative SLP when the AO index is positive) dominates the AO tripole. Atmospheric skewness is also discussed by Holzer (1996). The tendency for model-simulated modes to be skewed is also found in simplified models. In a study of zonal-jet vacillation in a simple primitive equations model, Koo et al. (2001, manuscript submitted to J. Climate) found very marked skewing of the same sense in the distribution of midlatitude jet intensity.

\section{d. Gaussian mixtures}

It has been argued that there is a close relationship between a system's underlying dynamics and its leading EOFs (Mo and Ghil 1987). On the other hand, the orthogonality constraint and assumed linearity often limits the dynamical scope of EOFs. EOFs- 1 and -2 of the intraseasonal data are much less well separated in variance than in the case of monthly SLP, so that the dynamical significance of the EOF-1 is less clear. To test the robustness of the EOF results to the methodology, daily NH height maps were analyzed by fitting a Gaussian mixture model to the PDF constructed in the subspace of the leading two EOFs. This analysis is based on the weather- or circulation-regime paradigm, in which the PDF is assumed to be generated by essentially low-order (chaotic) dynamics, leading to preferred regions of the phase space, or "regimes" (Legras and Ghil 1985). Smyth et al. (1999) have shown that observed daily NH geopotential heights can be well described by a mixture model comprising three Gaussian components. Cross-validated likelihood was used to determine the best value of $k$, the number of components or clusters.

Following the procedure of Smyth et al. (1999), we fit the mixture model in a 2D subspace of the data defined by the two leading EOFs of low-pass-filtered daily 700-hPa geopotential height. As before, the NovemberMarch daily data was first deseasonalized by subtracting the mean seasonal cycle of 5-day running means, prior to applying a 10-day low-pass filter; the resulting seasons are 128 days long starting on 12 November. The unfiltered deseasonalized data were then projected into the EOF subspace of the filtered data, and the PDF was analyzed.

The mixture model was computed for the 50-winter reanalysis dataset, as well as the 100-winter ECHAM3 and ECHAM4/OPYC control simulation datasets. For 
a) NCEP $1948-99(10.1 \%)$

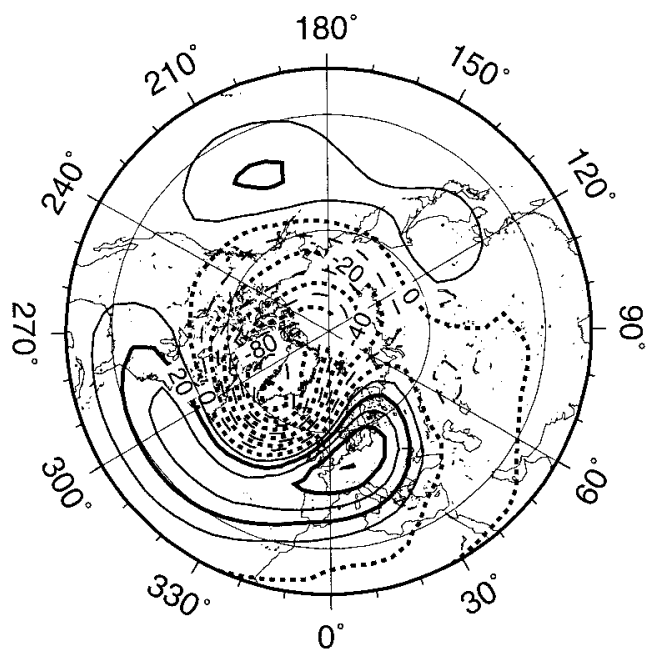

c) ECHAM4/OPYC CTRL (12.7\%)

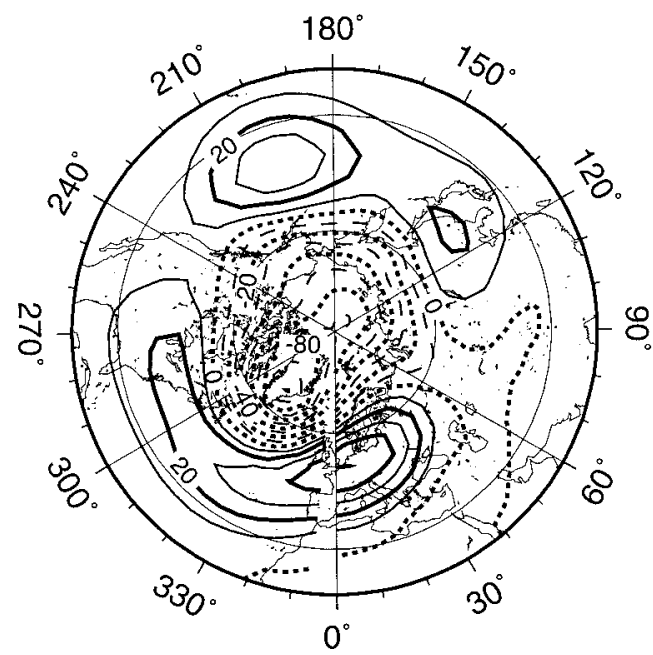

b) ECHAM3 CTRL (11.8\%)

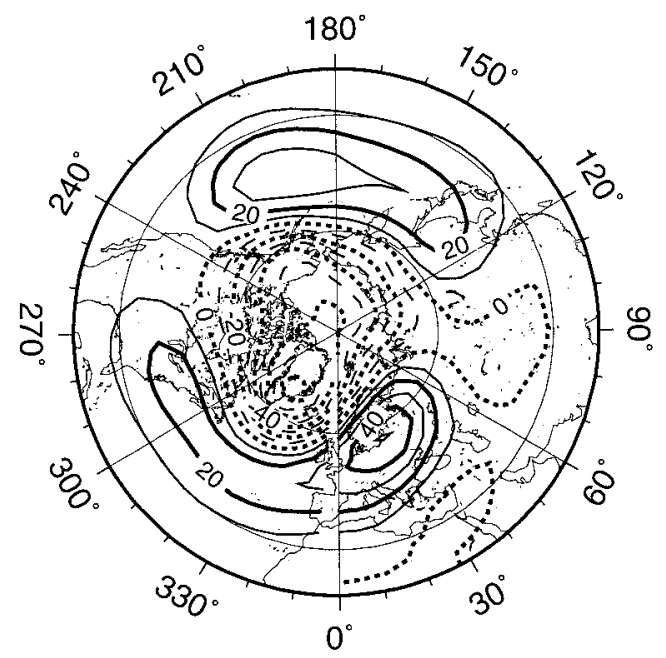

d) ECHAM4/OPYC GHG (11.0\%)

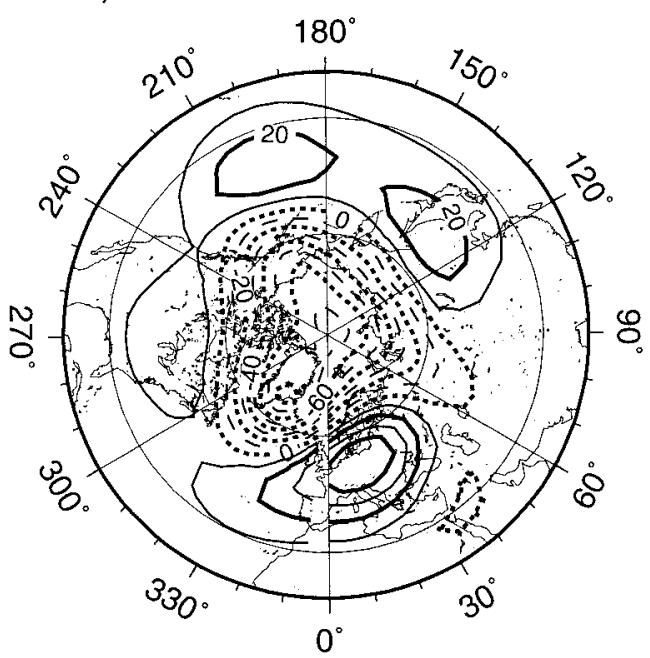

FIG. 7. EOF-1 of daily hemispheric 700-hPa geopotential height (Nov-Mar). (a) NCEP-NCAR reanalysis (194899), (b) ECHAM3, (c) ECHAM4/OPYC control, and (d) ECHAM/OPYC GHG. Contour interval is 10 gpm, with zero and negative contours dashed. The variance of the associated PC is given in brackets in percent of total; PC-2 (not shown) accounts for $7.8 \%, 8.4 \%, 7.8 \%$, and $8.9 \%$ of the variance for (a)-(d), respectively.

the GHG simulation, the entire 1860-2100 dataset is used, detrended by considering only deviations from seasonal means.

Table 3 gives the cross-validated log likelihood of particular values of $k$, the number of Gaussian components, together with the associated (posterior) probability of $k$, determined using cross validation by repeatedly dividing the data at random 20 times into two equal subsets. The log likelihoods are relative values and from which the posterior probabilities are derived via Bayes's rule, assuming that each value of $k=1, \ldots, 6$ is equally likely a priori (Smyth et al. 1999). Corroborating the results obtained with 44 DJF observed winters by Smyth et al. (1999), $k=3$ is clearly the most likely value of $k$ in the reanalysis dataset. We also obtain $k=3$ for the uncoupled
ECHAM3 simulation and for the ECHAM4/OPYC control run. For the ECHAM4/OPYC GHG run, the method indicates $k=4$ to be the most probable.

The centroids of the Gaussians are plotted in physical space in Fig. 10. The regime centroids of the reanalysis data have spatial patterns that resemble the three hemispheric regimes obtained by Cheng and Wallace (1993) and Smyth et al. (1999) very closely. These regime centroids show a greater degree of zonal asymmetry than the leading observed EOF in Fig. 7a, that was interpreted as the AO in section $4 \mathrm{a}$ (the EOFs of the lowpass-filtered data are very similar). The ECHAM3 simulation's regimes are more zonally symmetric and AOlike, with regimes 1 and 2 resembling opposite polarities of EOF-1, with regime 3 being close to the climatolog- 
a) NCEP

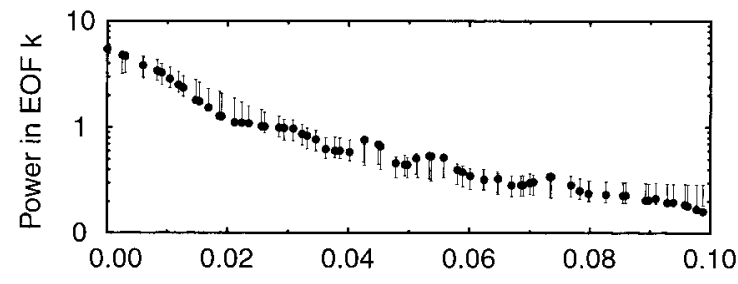

c) ECHAM4/OPYC Control

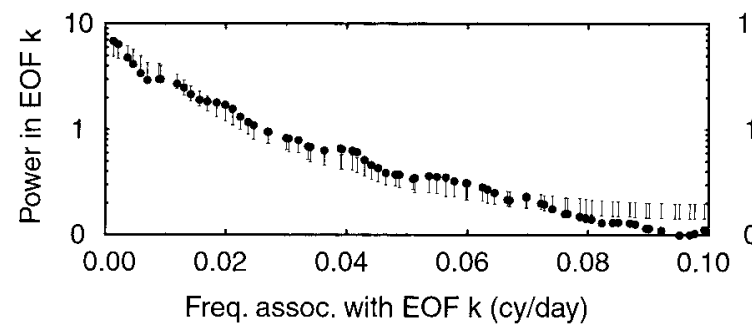

b) $\mathrm{ECHAM} 3$

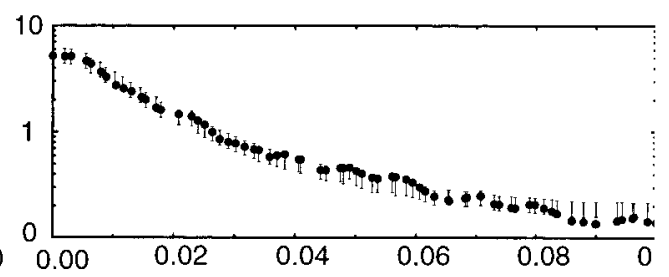

FIG. 8. Intraseasonal SSA power spectra of AO constructed from 5-day means of PC-1 of daily data (cycles per day). A window width of $1 \mathrm{yr}$ (i.e., $M=73$ 5-day means) was used, with details as in Fig. 2: (a) NCEP-NCAR reanalysis (1948-99), (b) ECHAM3, (c) ECHAM4/OPYC control, and (d) ECHAM4/OPYC GHG. Robust MTM estimates of $\gamma$ computed over the frequency range $1 /(4$ months) $-1 /(5$ days $)$ are (a) 0.585 , (b) 0.606 , (c) 0.578 , and (d) 0.651 .

ical mean. In the coupled control run, the influence of the PNA pattern becomes visible in regimes 1 and (especially) 3 , yielding patterns that are quite similar to the observed ones.

The regime centroids tend, in general, to fall off the axes in the 2D EOF subspace and therefore are linear combinations of EOF-1 and -2. Since EOF-2 is PNAlike in all cases, it appears that annular variability cannot be separated from wavelike PNA patterns, and this is especially true when ocean-atmosphere interaction is included. The regime centroids thus indicate that the $\mathrm{AO}$ is more complex than the leading EOF would indicate, in keeping with previous regime analyses (e.g., Kimoto and Ghil 1993; Corti et al. 1999; Monahan et al. 2000).

In the 1860-2100 GHG simulation, the mixture model suggests four regimes. However, the centroids of two of these are very similar in pattern, with the fourth regime being farther from the origin. We thus show the result obtained with $k=3$, which closely reproduces three of the four regimes. Of these three, regimes 2 and 3 are quite close to those in the coupled control run, while regime 1 is even more like the reverse PNA pattern, and is close to the axis of PC-2 (not shown).

The ECHAM4/OPYC GHG simulation's regimes (Fig. 10d) were computed from intraseasonal anomalies, after subtraction of the individual winter means. By construction, there can be no trend in regime membership. However, it is of interest to know how the GHG-induced trends project onto these strictly intraseasonal regimes, analogous to Fig. 6 for the SLP EOFs. Changes in the frequency-of-occurrence of circulation regimes has been found in GCMs with prescribed GHG increases (Monahan et al. 2000; Hsu and Zweirs 2001), while the observed record is more ambiguous (Corti et al. 1999; Hsu and Zweirs 2001). Figure 11 shows 30winter running averages of the frequency of regime occurrence, using the unfiltered data. These were computed by 1) projecting the unfiltered $700-\mathrm{hPa}$ height maps onto the leading two intraseasonal EOFs and 2) associating each map's location in this 2D PC plane with the closest regime centroid, using the intraseasonal regimes in Fig. 10d. The frequency-of-occurrence of regime 1 shows an upward trend at the expense of regimes 2 and 3 that both become less frequent. The trend is thus identified here with a reverse PNA-like pattern, in contrast to the AO pattern indicated by the EOF projection in Fig. 6.

\section{Summary and discussion}

Both the Hamburg and NCAR GCMs reproduce well the spatial structure of the AO, defined as the leading EOF of monthly mean SLP. The results clearly indicate the $\mathrm{AO}$ to be an intrinsic mode of the atmosphere, because it occurs in the uncoupled models forced by climatological SST. The AO also emerges as the leading EOF of daily December-March 700-hPa geopotential height maps in the Hamburg models, with rather minor structural differences in comparison with the monthly data.

Like the observed data analyzed by Smyth et al. (1999), and examined here using the NCEP-NCAR reanalysis dataset, the PDFs of the Hamburg models are 
a) NCEP Reanalysis

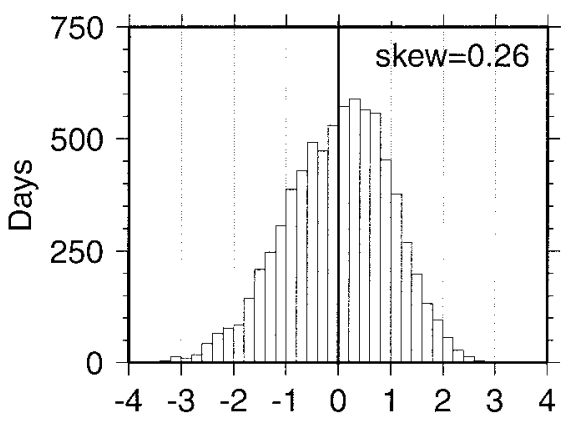

c) ECHAM4/OPYC CTRL

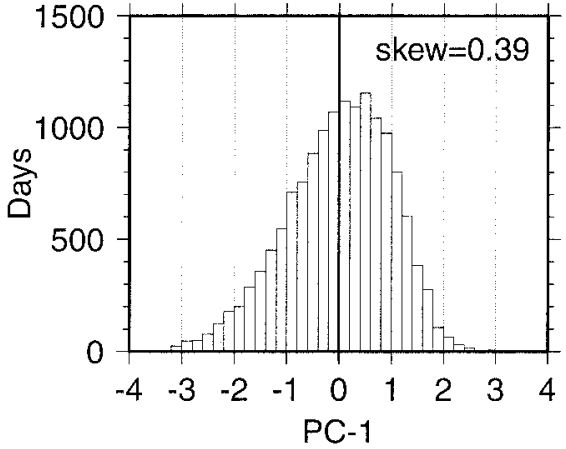

b) ECHAM3 CTRL

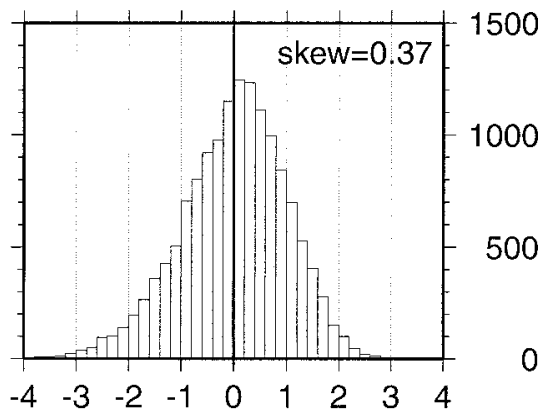

d) ECHAM4/OPYC GHG

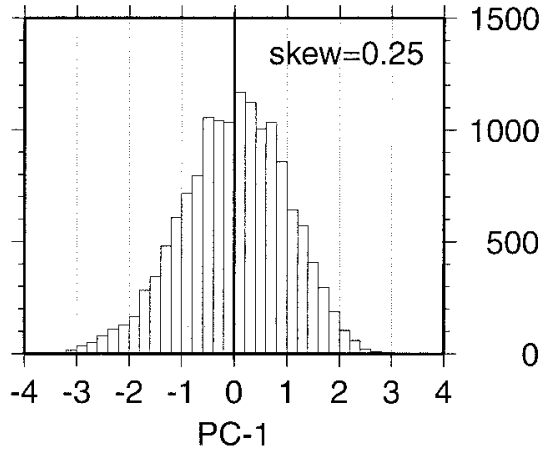

FIG. 9. Histograms of daily PC-1: (a) NCEP-NCAR reanalysis (1948-99), (b) ECHAM3, (c) ECHAM4/OPYC control, and (d) ECHAM4/OPYC GHG. The skewness Skew $\left(x_{1}, \ldots\right.$, $\left.x_{N}\right)=1 / N \sum_{j=1}^{N}\left[\left(x_{j}-\bar{x}\right) / \sigma\right]^{3}$ is noted in each panel. Its standard deviation is given approximately by $\sigma_{\text {skew }} \simeq \sqrt{15 / N}$ (e.g., Press et al. 1986), which yields $\sigma_{\text {skew }} \simeq 0.142$ in (a) and $\sigma_{\text {skew }}$ $\simeq 0.102$ in (b)-(d), assuming $N / 10$ effective degrees of freedom.

found to be best approximated by three underlying Gaussian clusters, corresponding to recurrent circulation regimes. The spatial structures of the simulated regimes are found to be quite realistic, especially in the ECHAM4/OPYC coupled control run. However, large differences in regime structure are found between the simulations, as compared to the leading EOF. While the regime patterns may be more prone to sampling variability, they do suggest that it may not be dynamically meaningful to separate the annular component from the PNA-like component. The latter is weak in the uncoupled ECHAM3 but becomes stronger in the coupled runs, consistent with the influence of ENSO-like variability.

The Pacific pole of EOF-1 is stronger than observed in the uncoupled and coupled runs of both GCMs. This is consistent with the intraseasonal regimes that are more AO-like in the simulations than in observations, with the exception of the ECHAM4/OPYC GHG run. While the concept of an important annular mode in observed Northern Hemisphere SLP is controversial (Deser 2000), the concept does appear to be more relevant to the GCM simulations. An annular mode is clearly the dominant one in aquaplanet GCM studies (e.g., Feldstein and Lee 1996), and an overly annular mode was found also found in the GCM study of Bladé (1997). Its relative strength in the GCMs studied here suggests that these models may be lacking in the physics that regionalizes the annular mode over the North Atlantic in reality. The climatological stationary waves are well simulated by both models. One possibility is that forcing from the tropical Pacific strongly disrupts the annular mode over the North Pacific in the real world. Even in the models, the simple notion of symmetry between the opposite polarities of the AO starts to break down in coupled runs, where model ENSOlike variability, though weak, appears to lead to a more vigorous PNA component that influences regime structure.

An upward trend in the AO index does occur in the GHG run of the Hamburg model. However, it is shown that this is due largely to changes over the North Pacific and that the trend in SLP does not resemble the AO pattern. The reverse PNA-like regime becomes particularly pronounced in the 1860-2100 GHG run, and its frequency-of-occurrence shown an upward trend. This finding is consistent with the study of Timmermann et al. (1999), who found that ENSO variability in the ECHAM4/OPYC model becomes skewed toward stronger La Niña events; these would tend to generate the 


\section{a) NCEP}

\#1

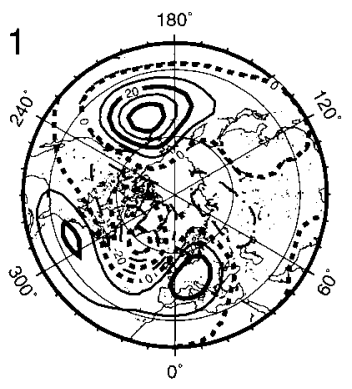

b) ECHAM3

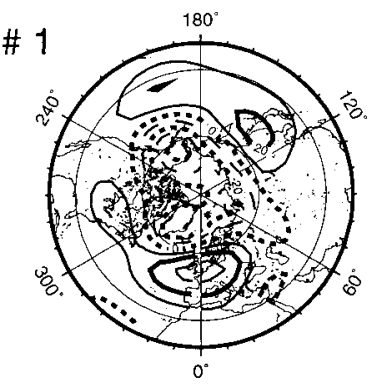

\#2

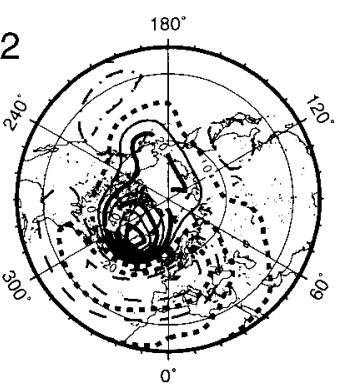

\# 2

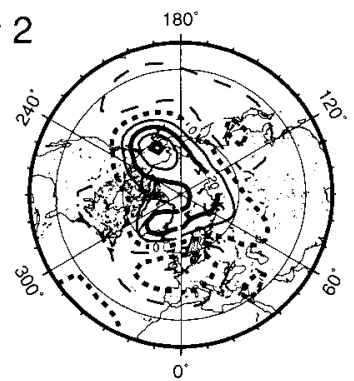

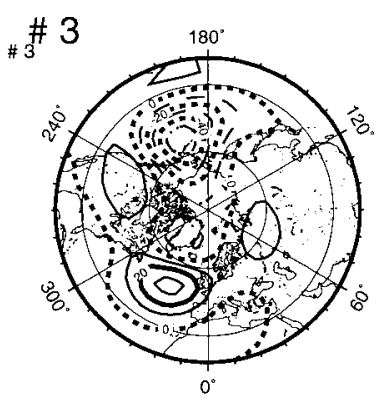

\# 3

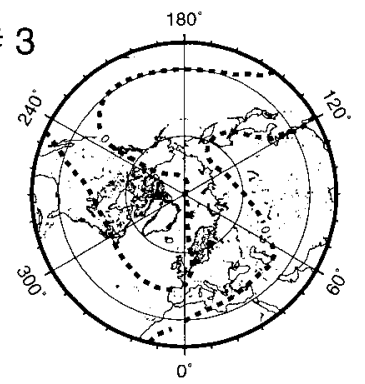

\section{c) ECHAM4/OPYC Control}
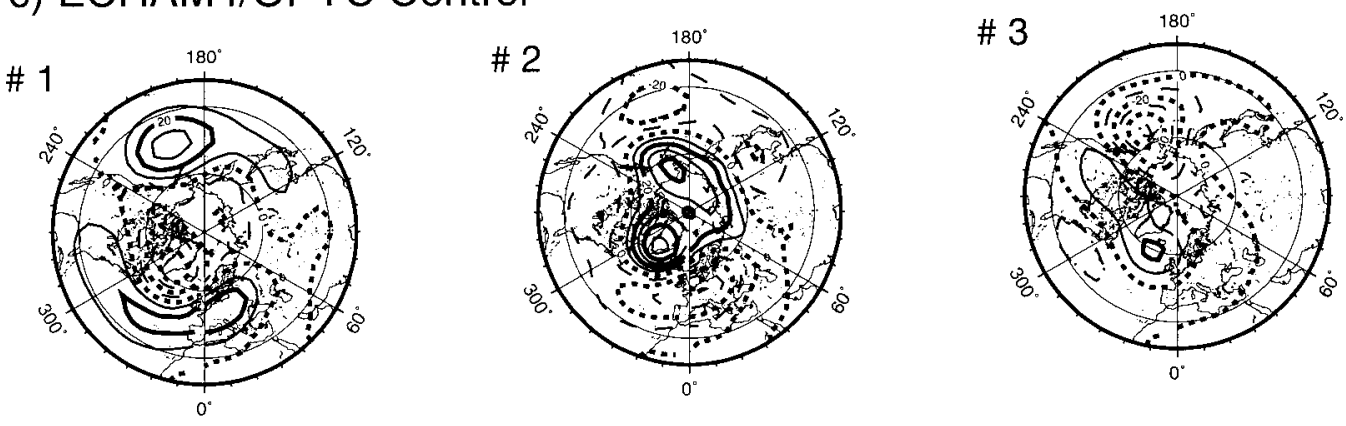

\section{d) ECHAM4/OPYC GHG}
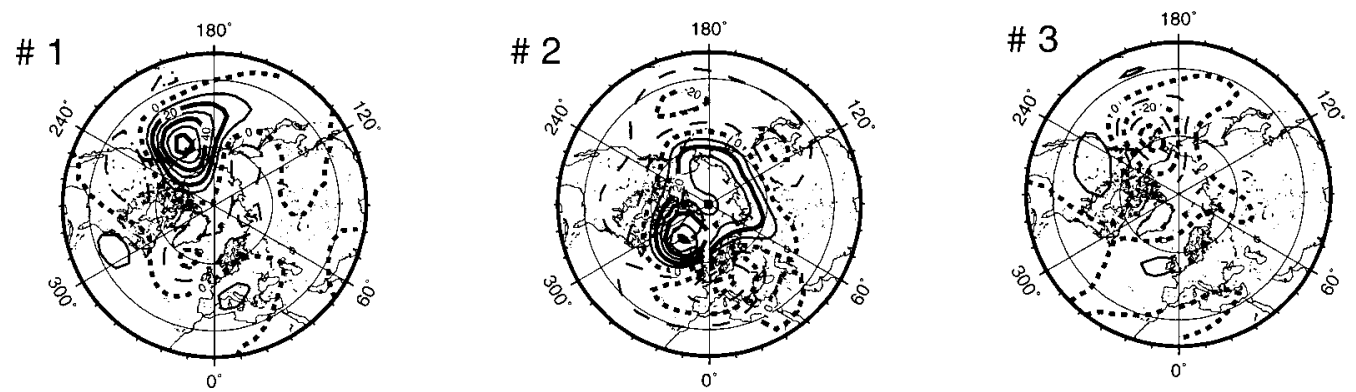

FIG. 10. Centroids of Gaussian mixture model applied to low-pass-filtered daily data. The maps show the 700-hPa height anomalies at each centroid; contour interval is $10 \mathrm{gpm}$ : (a) NCEP-NCAR reanalysis (1948-99), (b) ECHAM3, (c) ECHAM4/OPYC control, and (d) ECHAM4/OPYC GHG 1860-2100 (detrended).

reverse PNA-like pattern which projects in this case onto the AO pattern giving rise to an apparent trend in the latter.

While the hemispheric patterns derived here are not appropriate for detecting regional-scale features, we note that Ulbrich and Christoph (1999) have reported a systematic shift of the NAO's northern variability center in the same ECHAM4/OPYC experiment, from a po- 


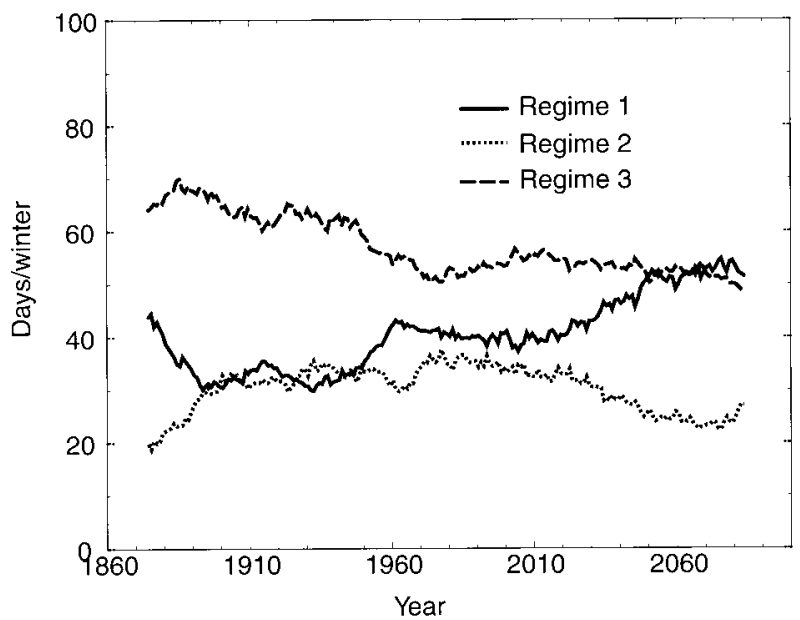

FIG. 11. The 30-yr running means of regime frequency-ofoccurrence for the ECHAM4/OPYC GHG simulation.

sition close to the east coast of Greenland, where it is located in the control run, to the Norwegian Sea.

The spectrum of the observed AO, constructed from Thompson and Wallace's (2000) near-century-long series using SSA, exhibits a near-decadal oscillatory component with a nominal periods $9.0 \mathrm{yr}$. The latter is recovered with $95 \%$ statistical significance from Jones et al.'s (1997) 175-yr record of the NAO, with a nominal period of $8.0 \mathrm{yr}$. No clear evidence of similar oscillations was found in the coupled GCM simulations, despite the longer (300 yr) records available. The simulated AO spectra are "white" in appearance, and the lag-1 autocorrelation is not found to increase significantly in the coupled simulations compared to the uncoupled ones.

Even on the intraseasonal timescale there is no measurable reddening of the spectrum in the coupled control run. In principle, we would expect atmospheric anomalies to be less thermally damped when SSTs are allowed the freedom to adjust to surface fluxes and thus for the spectrum to be redder (Barsugli and Battisti 1998). However, the model simulations suggest that this effect is negligible for the hemispheric-scale deep equivalent barotropic structure of the AO. This result can be compared to that of Bladé (1997) who investigated the effect of coupling using a low-resolution atmospheric GCM coupled to an oceanic slab mixed layer in a perpetual January experiment. Bladé (1997) found a large increase in low-level thermal variance due to the coupling but only a very small increase in the 500-hPa geopotential variance. Nonetheless, she found a slight reddening of the $\mathrm{AO}$ spectrum at $500 \mathrm{hPa}$.

Intraseasonal oscillations with periods near 20 days are found in the AO, consistent with Lott et al. (2001) who have presented evidence that mountain torques play an active role in these oscillations. Similar significant spectral peaks are also found in the model simulations. However, the GHG simulation shows less-clear evi- dence of these oscillations, suggesting that interactions with topography might be less pronounced in this case because of differences of the AO's spatial distribution.

The spectra imply that ocean-atmosphere interaction exerts little influence on the AO time series. This finding agrees with Saravanan's (1998) finding for the NAO in CCM3 in which prescribing the observed monthly evolution of SST did not increase the variance of the NAO. However, it contrasts with Robertson et al. (2000) who found that the University of California, Los Angeles atmospheric general circulation model's NAO became much more vigorous when the observed monthly evolution of SST was prescribed over the Atlantic, when compared with a control run with monthly climatological SSTs prescribed. It also contrasts with Rodwell et al. (1999) and Mehta et al. (2000) who were able to reproduce the low-frequency component of the NAO over the past half-century, including the trend, using large ensembles of atmospheric GCM simulations with the observed evolution of global SSTs and sea ice prescribed. Further work is required to resolve these important intermodel differences in result.

Acknowledgments. It is a pleasure to thank M. Ghil, R. Saravanan, G. Schmidt, and D. Thompson for stimulating discussions, and three reviewers whose comments led to a substantial improvements in the manuscript. I also thank M. Latif and the Max Planck Institute for their hospitality during a 2-week stay in the summer of 1998 when this work was initiated, and for making the GCM simulations available. The CSM group at NCAR are equally acknowledged for allowing access to their simulations. The NCEP-NCAR reanalysis data were provided through the NOAA Climate Diagnostics Center (http://www.cdc.noaa.gov/). This work was supported by DOE Grant DE-FG03-98ER62615. This is Publication Number 5663 of UCLA's Institute of Geophysics and Planetary Physics (IGPP).

\section{REFERENCES}

Allen, M. R., and L. A. Smith, 1996: Monte Carlo SSA: Detecting irregular oscillations in the presence of colored noise. J. Climate, 9, 3373-3404.

Baldwin, M. P., and T. J. Dunkerton, 1999: Propagation of the Arctic oscillation from the stratosphere to the troposphere. J. Geophys. Res., 104, 30 937-30946.

Barsugli, J. J., and D. S. Battisti, 1998: The basic effects of atmosphere-ocean thermal coupling on midlatitude variability. J. Atmos. Sci., 55, 477-493.

Bladé, I., 1997: The influence of midlatitude ocean-atmosphere coupling on the low-frequency variability of a GCM. Part I: No tropical SST forcing. J. Climate, 10, 2087-2106.

Boville, B. A., and P. R. Gent, 1998: The NCAR Climate System Model, version one. J. Climate, 11, 1115-1130.

__ , and J. W. Hurrell, 1998: A comparison of the atmospheric circulations simulated by CCM3 and CSM1. J. Climate, 11, 1327-1341.

Bretherton, C. S., and D. S. Battisti, 2000: An interpretation of the results from atmospheric circulation models forced by the time 
history of the observed sea surface temperature distribution. Geophys. Res. Lett., 27, 767-770.

Cayan, D. R., 1992: Latent and sensible heat flux anomalies over the northern oceans: Driving the sea surface temperature. J. Phys. Oceanogr., 22, 859-881.

Cheng, X., and J. M. Wallace, 1993: Cluster analysis of the Northern Hemisphere wintertime 500-hPa height field: Spatial patterns. $J$. Atmos. Sci., 50, 2674-2696.

Corti, S., F. Molteni, and T. N. Palmer, 1999: Signature of recent climate change in frequencies of natural atmospheric circulation regimes. Nature, 398, 799-802.

Davis, R. E., 1976: Predictability of sea surface temperature and sea level pressure over the North Pacific. J. Phys. Oceanogr., 6, 249-266.

Deser, C., 2000: On the teleconnectivity of the "Arctic oscillation." Geophys. Res. Lett., 27, 779-782.

Dettinger, M. D., M. Ghil, and C. L. Keppenne, 1995: Interannual and interdecadal variability in United States surface-air temperatures, 1910-87. Climatic Change, 31, 35-66.

Feldstein, S. B., 2000: The timescale, power spectra, and climate noise properties of teleconnection patterns. J. Climate, 13, 44304440 .

— aquaplanet GCM. J. Atmos. Sci., 53, 3541-3555.

Fyfe, J. C., G. J. Boer, and G. M. Flato, 1999: The Arctic and Antarctic oscillations and their projected changes under global warming. Geophys. Res. Lett., 26, 1601-1604.

Ghil, M., and Coauthors, 2001: Advanced spectral methods for climatic time series. Rev. Geophys., in press

Gillett, N. P., M. P. Baldwin, and M. R. Allen, 2001: Nonlinearity in the stratospheric response to external forcing. J. Geophys. Res., 106, 7891-7902.

Graf, H.-F., J. Perlwitz, I. Kirchner, and I. Schutt, 1995: Recent northern winter climate trends, ozone changes and increased greenhouse forcing. Contrib. Atmos. Phys., 68, 233-248.

Holzer, M., 1996: Asymmetric geopotential height fluctuations from symmetric winds. J. Atmos. Sci., 53, 1361-1379.

Hsu, C. J., and F. W. Zweirs, 2001: Climate change in recurrent regimes and modes of Northern Hemisphere atmospheric variability. J. Geophys. Res., in press.

Hurrell, J. W., 1995: Decadal trends in the North Atlantic oscillation: Regional temperature and precipitation. Science, 269, 676-679.

Jones, P. D., T. Jonsson, and D. Wheeler, 1997: Extension using early instrumental pressure observations from Gibraltar and SW Iceland to the North Atlantic oscillation. Int. J. Climatol., 17, $1433-$ 1450

Kalnay, E., and Coauthors, 1996: The NCEP/NCAR 40-Year Reanalysis Project. Bull. Amer. Meteor. Soc., 77, 437-470.

Kimoto, M., and M. Ghil, 1993: Multiple flow regimes in the Northern Hemisphere winter. Part I: Methodology and hemispheric regimes. J. Atmos. Sci., 50, 2625-2643.

Kutzbach, J. E., 1970: Large-scale features of monthly mean Northern Hemisphere anomaly maps of sea level pressure. Mon. Wea. Rev., 98, 708-716.

Latif, M., and T. P. Barnett, 1994: Causes of decadal climate variability over the North Pacific/North American sector. Science, 266, 634-637.

Lau, N.-C., 1981: A diagnostic study of recurrent meteorological anomalies appearing in a 15-year simulation with a GFDL general circulation model. Mon. Wea. Rev., 109, 2287-2311.

Legras, B., and M. Ghil, 1985: Persistent anomalies, blocking and variations in atmospheric predictability. J. Atmos. Sci., 42, 433471.

Lorenz, E. N., 1951: Seasonal and irregular variations of the Northern Hemisphere sea-level pressure profile. J. Meteor., 8, 52-59.

Lott, F., A. W. Robertson, and M. Ghil, 2001: Mountain torques and intraseasonal atmospheric oscillations. Geophys. Res. Lett., 28, $1207-1210$.

Mann, M. E., and J. M. Lees, 1996: Robust estimation of background noise and signal detection in climatic time series. Climate Change, 33, 409-445.

Mehta, V. M., M. J. Suarez, J. V. Manganello, and T. L. Delworth, 2000: Oceanic influence on the North Atlantic oscillation and associated Northern Hemisphere climate variations: 1959-1993. Geophys. Res. Lett., 27, 121-124.

Mo, K. C., and M. Ghil, 1987: Statistics and dynamics of persistent anomalies. J. Atmos. Sci., 44, 877-901.

Monahan, A. H., J. C. Fyfe, and G. M. Flato, 2000: A regime view of Northern Hemispheric atmospheric variability and change under global warming. Geophys. Res. Lett., 27, 1139-1142.

Moron, V., R. Vautard, and M. Ghil, 1998: Trends, interdecadal and interannual oscillations in global sea-surface temperatures. Climate. Dyn., 14, 545-569.

Nakamura, H., and J. M. Wallace, 1991: Skewness of low-frequency fluctuations in the tropospheric circulation during the northern winter. J. Atmos. Sci., 48, 1441-1448.

Plaut, G., M. Ghil, and R. Vautard, 1995: Interannual and interdecadal variability in 335 years of central England temperature. Science, 268, 710-713.

Press, W. H., B. P. Flannery, S. A. Teukolsky, and W. T. Vetterling, 1986: Numerical Recipes. Cambridge University Press, 818 pp.

Rayner, N. A., C. K. Folland, D. E. Parker, and E. B. Horton, 1995: A new global sea-ice and sea surface temperature (GISST) data set for 1903-1994 for forcing climate models. Hadley Centre Internal Note 69, 13 pp.

Robertson, A. W., C. R. Mechoso, and Y.-J. Kim, 2000: The influence of Atlantic sea surface temperature anomalies on the North Atlantic oscillation. J. Climate, 13, 122-138.

Rodwell, M. J., D. P. Rowell, and C. K. Folland, 1999: Oceanic forcing of the wintertime North Atlantic oscillation and European climate. Nature, 398, 320-323

Roeckner, E., and Coauthors, 1996: The atmospheric general circulation model ECHAM4: Model description and simulation of present-day climate. Max-Planck-Institut für Meteorologie Rep. $218,90 \mathrm{pp}$

- L. Lengtsson, J. Feichter, J. Lelieveld, and H. Rodhe, 1999: Transient climate change simulations with a coupled atmosphere-ocean GCM including the tropospheric sulfur cycle. $J$. Climate, 12, 3004-3032.

Rogers, J. C., 1984: The association between the North Atlantic oscillation and the Southern Oscillation in the Northern Hemisphere. Mon. Wea. Rev., 112, 1999-2015.

Saravanan, R., 1998: Atmospheric low-frequency variability and its relationship to midlatitude SST variability: Studies using the NCAR climate system model. J. Climate, 11, 1386-1404.

-, and J. C. McWilliams, 1997: Stochasticity and spatial resonance in interdecadal climate fluctuations. J. Climate, 10, 2299-2320.

Shindell, D. T., R. L. Miller, G. A. Schmidt, and L. Pandolfo, 1999: Simulation of recent northern winter climate trends by greenhouse-gas forcing. Nature, 399, 452-455.

Smyth, P., M. Ghil, and K. Ide, 1999: Multiple regimes in Northern Hemisphere height fields via mixture model clustering. J. Atmos. Sci., 56, 3704-3723.

Stephenson, D. B., V. Pavan, and R. Bojariu, 2000: Is the North Atlantic oscillation a random walk? Int. J. Climatol, 20, 1-18.

Thompson, D. W. J., and J. M. Wallace, 1998: The Arctic oscillation signature in the wintertime geopotential height and temperature fields. Geophys. Res. Lett., 25, 1297-1300.

- , and J. M. Wallace, 2000: Annular modes in the extratropical circulation. Part I: Month-to-month variability. J. Climate, 13, 1000-1016.

Timmermann, A., J. Oberhuber, A. Bacher, M. Esch, M. Latif, and E. Roeckner, 1999: ENSO response to greenhouse warming: Increased El Niño frequency in a climate model forced by future greenhouse warming. Nature, 398, 694-697.

Trenberth, K. E., and D. A. Paolino Jr., 1981: Characteristic patterns of variability of sea level pressure in the Northern Hemisphere. Mon. Wea. Rev., 109, 1169-1189.

Ulbrich, U., and M. Christoph, 1999: A shift of the NAO and in- 
creasing storm track activity over Europe due to anthropogenic greenhouse gas forcing. Climate Dyn., 15, 551-559.

Vautard, R., and M. Ghil, 1989: Singular spectrum analysis in nonlinear dynamics, with applications to paleoclimatic time series. Physica D, 35, 395-424.

Wallace, J. M., and D. S. Gutzler, 1981: Teleconnections in the geo- potential height field during the Northern Hemisphere winter. Mon. Wea. Rev., 109, 784-812.

White, G. H., 1980: Skewness, kurtosis and extreme values of Northern Hemisphere geopotential heights. Mon. Wea. Rev., 108, 1446-1455. Wunsch, C., 1999: The interpretation of short climate records. Bull. Amer. Meteor. Soc., 80, 245-255. 